\title{
SIGNIFICANCE OF FLAT EPITHELIAL LESIONS OF THE URINARY BLADDER IN EARLY DETECTION OF BLADDER CANCER: HISTOPATHOLOGICAL AND IMMUNOHISTOCHEMICAL STUDY
}

\author{
Mohamed A. Ramadan, Masoud M. Omar, Mona R. Abdel-Wahed \\ and Shimaa A. Ahmed \\ Pathology Department, Faculty of Medicine, Zagazig University
}

ABSTRACT
Background: Urothelial carcinoma of the urinary bladder is the second most common malignancy of the
genitourinary system, after prostate cancer. The flat lesions are classified into flat lesions without cytological
atypia (Flat hyperplasia) and flat lesions with cytological atypia; reactive atypia, atypia of unknown
significance, urothelial dysplasia and urothelial carcinoma in situ). The immunohistochemical markers such
as cytokeratin 20,CD 44 and Ki 67 may be useful in differentiating CIS from reactive changes in difficult
biopsy cases.
Aim: This study was conducted to determine the role of cytokeratin 20, CD 44 and Ki 67 in the diagnosis of
dysplasia and other flat lesions of the urinary bladder.
Methods: Sixty representative cases for flat urothelial lesions of urinary bladder were examined
immunohistochemically using antibodies against CD44, cytokeratin 20 and Ki-67.
Results: CD 44 were positive in $100 \%$ of cases of reactive urothelial atypia, but flat Hyperplasia and CIS
cases were negative. However CD 44 were positive in $42.9 \%$ of atypia of unknown significance and
$14.3 \%$ of Dysplasia. CK 20 were positive in (95.5\%) of Dysplasia. Non of Flat Hyperplasia were positive for
CK 20. However CK 20 was positive in $88.2 \%$ of CIS, 57.1\% of atypia of unknown significance and
$7.1 \%$ of reactive urothelial atypia. ki 67 index were high in $82.4 \%$ of cases of CIS, non of flat hyperplasia
expressed high ki 67 index. However ki 67 index were high in $57.1 \%$ of atypia of unknown significance,
$52.4 \%$ of dysplasia and $14.3 \%$ of reactive urothelial atypia.
Conclusion. CD 44 is the most constant marker in the reactive urothelium. CK20 is the most commonly
detected marker in the dysplastic urothelium. Nevertheless, the most accurate is application of an
immunohistochemical panel composed of the three antibodies (standard CD 44 , CK20 and Ki-67) together
with correlation with morphology. This is very useful for confirming the presence of dysplastic changes in
the urothelium and differentiating reactive urothelium from dysplastic urothelium (dysplasia/CIS).
Keywords: Flat epithelial lesions, CD44, cytokeratin ck20, ki67, immunohistochemistry.

\section{INTRODUCTION}

B ladder cancer is a significant public health problem worldwide. It is the fourth most common cancer in men, accounting for $6.9 \%$ of all cancers, and tenth most common cancer in women, accounting for $2.6 \%$ of all cancers ${ }^{(\mathbf{1})}$. In Egypt, it constitutes $30.3 \%$ of all cancers ${ }^{(2)}$.

In 2004 World Health Organization classification, the flat-related preneoplastic lesions of the urinary bladder are classified as; urothelial hyperplasia ,reactive urothelial atypia, urothelial atypia of unknown significance(AUS(, urothelial dysplasia and urothelial carcinoma in $\operatorname{situ}(\mathrm{CIS})^{(\mathbf{3})}$. Reactive atypia denotes mild nuclear abnormalities occurring in acutely or chronically inflamed urothelium which may be normal or slightly thickened. Frequent mitoses may involve the lower layers of the urothelium.The significance of reactive atypia is to differentiate it from dysplasia, and $\operatorname{CIS}^{(\mathbf{4})}$.

Atypia of unknown significance describes lesions with nuclear abnormalities similar to those of reactive changes (fewer than those of dysplasia), but out of proportion to the degree of inflammation $^{(5)}$.

Dysplasia showed architectural and Cytologic abnormalities falling short of the diagnostic threshold for carcinoma in situ. The cytologic features are restricted to intermediate and basal cells and less atypical than in carcinoma in situ. The thickness of dysplastic urothelium is usually normal, but it may be increased or decreased $^{(6,7)}$.

Urothelial dysplasia may be primary dysplasia (rare) or secondary (more frequent) which is associated with papillary urothelial neoplasms and has higher rate of progression to carcinoma than primary dysplasia ${ }^{(\mathbf{1})}$.

Carcinoma in situ (CIS) of the urinary bladder is defined by the replacement of part or all of the normal epithelium by cells that have microscopic and molecular features of carcinoma, yet are confined to the epithelium ${ }^{(8)}$.

CIS may occur as; (1) primary CIS occurring without associated previous urothelial tumor, (2) concomitant CIS, occurring in conjunction with a newly diagnosed bladder tumor 
(3) secondary CIS, diagnosed during follow-up of a known bladder tumor, with or without a concomitant tumor ${ }^{(\mathbf{4 , 9})}$.

CD44 is a transmembrane glycoprotein involved in cell-cell and cell-matrix interactions. In the normal urothelium, CD44 staining is limited to the basal region ${ }^{(\mathbf{1 0})}$. The urothelium in reactive atypia typically shows staining with CD44 in a diffuse membranous full-thickness pattern or with patchy basal and intermediate cell expression. This is in contrast to absence of CD44 staining in dysplasia and Carcinoma in situ. It is important to note that these staining patterns are not absolute and correlation with morphology is critical ${ }^{(11,12)}$. Cytokeratin20 (CK20) is the most recently identified type I keratin protein showing a limited pattern of expression in normal tissues and its expression is maintained in malignant tissues ${ }^{(\mathbf{1 3})}$.

Normal urothelium typically exhibits CK20 staining in the umbrella cell layer, but reactive atypia lacks extensive staining for CK20 ${ }^{(\mathbf{1 0})}$. In AUS, there is CK20 expression in the deeper mucosal layers ${ }^{(\mathbf{1 4})}$. In Carcinoma in situ there is CK20 positivity throughout the neoplastic urothelium $^{(\mathbf{1 2})}$.

$\mathrm{Ki}-67$ is absent to positive in fewer than $10 \%$ of the basal and parabasal cells of normal urothelium, indicating a low proliferative rate ${ }^{(\mathbf{1 0})}$. Both Ki 67 and CK20 positivity throughout the neoplastic urothelium with negative CD44 favors a diagnosis of Carcinoma in situ ${ }^{(\mathbf{1 2})}$.

\section{MATERIAL AND METHODS}

This study included paraffin blocks of 150 cases of bladder lesions selected from urinary bladder biopsy specimens diagnosed at Pathology Department, Faculty of Medicine, Zagazig University, Egypt, during the period from September 2008 to September 2011. The clinical data of the patients were obtained from medical files. Then 60 represetative cases of flat epithelial lesions of the urinary bladder were selected for immunohistochemical study.

\section{Histopathologic examination:}

Consecutive $4 \mu \mathrm{m}$ sections were prepared and stained with hematoxylin \& eosin for histopathological examination. Pathological diagnosis was made according to $2004 \mathrm{WHO} / 1998$ ISUP classification of urothelial neoplasms ${ }^{(7)}$.

\section{Immunohistochemical staining:}

Immunohistochemical staining was carried out using streptoavidin-biotin immunoperoxidase technique (Dako-Cytomation, Glostrup, Denmark). 3-5 $\mu \mathrm{m}$ thick sections cut from formalin-fixed, paraffin-embedded blocks, were deparaffinized in xylene and rehydrated in graded alcohol. Sections were boiled in citrate buffer ( $\mathrm{pH}$ 6.0) for $20 \mathrm{~min}$ and then washed in phosphate buffer saline $(\mathrm{pH}$ 7.3). Thereafter, blocking of endogenous peroxidase activity with $6 \% \mathrm{H} 2 \mathrm{O} 2$ in methanol was carried out. The slides were then incubated overnight with monoclonal antibodies; (CD 44 Std mouse monoclonal antibody Cat. from Thermo Scientific/Lab Vision Corporation, Fermont, USA, clone: $156-3 \mathrm{c} 11.0 .09 \%$ sodium azide. Dilution 1:100), (CK 20 mouse monoclonal antibody Cat from Thermo Scientific/Lab Vision Corporation, Fermont, USA, clone: Ks20.8. 0.09\% sodium azide. Dilution 1:50), (Ki-67 Rabbit Polyclonal antibody Cat from Thermo Scientific/Lab Vision Corporation, Fermont, USA, 0.09\% sodium azide. Dilution 1:300). Incubation with a secondary antibody and product visualization were performed (Dako Cytomation, Glostrup, Denmark) with diaminobenzidine substrate (Research Genetics, Huntsville, AL) as the chromogen. The slides were finally counterstained with Mayer's haematoxylin (BioGenex Laboratories, San Ramon, CA), and washed once each with distilled water and PBS. Tonsil specimens were used as a positive control for CD44 and ki67.F or ck20, colon carcinoma was used. Negative controls for CD44 and ki67 were obtained by substitution of primary antibodies with blocking buffer..For ck20 Negative controls were Immunoglobulin $\mathrm{G}(\mathrm{IgG})$.

Evaluation of the results of immunohistochemical staining:

1- Evaluation of CD 44 and CK 20 immunostaining:

Standard CD44 is membranous in distribution. CK20 is a cytoplasmic stain .The degree of reactivity for each antibody was graded from 0 to $4\left(0\right.$ _ negative; $1_{-}$weak, patchy $[<50 \%$ of the cells]; $2_{-}$moderate, patchy $[<50 \%$ of the cells]; 3 _ moderate, diffuse $[>50 \%$ of cells]; 4 strong, diffuse $[>50 \%$ of cells]). To designate overexpression for CD44 and CK 20 antibodies, we required $>50 \%$ of the urothelium to be moderately to strongly positive (3-4 positivity) ${ }^{(\mathbf{1 5})}$. 2- Evaluation of ki 67 immunostaining:

Ki-67 was regarded as positive when nuclei stained dark brown or contained dark brown granules. Ki-67 index was determined as the percentage of immunostained cells per 200 cells by 5 fields of view in each section ${ }^{(16)}$. Immunoreactivity to Ki-67 was "low" if nuclear staining $<15 \%$ and "high" if $>15 \%{ }^{(17)}$.

\section{Statistical analysis}

The results of the study were statistically analyzed using the SPSS software (SPSS, Chicago, IL, USA). Data were expressed as mean \pm SD for quantitative variables, as numbers and percentages. For categorical variables, the Student t-test was 
used. P-value less than 0.05 was considered significant.

\section{RESULTS}

In the present study, 60 cases of flat epithelial lesions of the urinary bladder were selected and classified according to 2004 WHO/1998 ISUP classification of urothelial neoplasms $^{(7)}$ into flat Hyperplasia $(1 / 60,1.7 \%)$, reactive atypia $(14 / 60,23.3 \%)$, atypia of unknown significance $(7 / 60,11.7 \%)$, dysplasia
$(21 / 60,35 \%)$ and carcinoma in situ (17/60, $28.3 \%)$.

The mean age of studied cases was 64 years and ranged between $45-77$ years. There is a significant association between age $>70$ and the presence of dysplasia and CIS. The majority of the studied cases were males. This supports the concept that CIS maintains the same age and sex predilection as invasive bladder cancer.

Table 1: Incidence of different selected flat lesions of the urinary bladder

\begin{tabular}{lccc}
\hline & Histological diagnosis & No & \% \\
\hline Flat hyperplasia & & 1 & 1.7 \\
\hline reactive urothelial & atypia & 14 & 23.3 \\
\hline atypia of unknown significance & 7 & 11.7 \\
\hline Dysplasia & 21 & 35.0 \\
\hline CIS & 17 & 28.3 \\
\hline Total & 60 & $100 \%$ \\
\hline
\end{tabular}

The majority of studied cases were dysplasia (35.0\%), followed by CIS.

Table2: Immunohistochemical reactivity pattern of CD 44 in selected flat lesions of the urinary bladder

Negative interpretation Positive interpretation $\quad \mathbf{X}^{2} \quad$ P

Flat lesions No

\begin{tabular}{lccccccc}
\cline { 3 - 6 } & & No & \% & No & \% & & \\
\hline Flat hyperplasia & 1 & 1 & 100.0 & 0 & 0.0 & 0.1 & 0.75 \\
\hline reactive urothelial atypia & 14 & 0 & 0.0 & $14^{* *}$ & 100.0 & 30.29 & $<0.001^{* *}$ \\
\hline atypia of unknown significance & 7 & 4 & 57.1 & 3 & 42.9 & 0.78 & 0.37 \\
\hline Dysplasia & 21 & $18^{*}$ & 85.7 & 3 & 14.3 & 6.09 & $0.013^{*}$ \\
\hline carcinoma in situ(CIS) & 17 & $17^{* *}$ & 100.0 & 0 & 0.0 & 12.77 & $<0.001^{* *}$ \\
\hline Total & 60 & 40 & 66.7 & 20 & 33.3 & &
\end{tabular}

CD 44 were positive in 100\% of cases of reactive urothelial atypia (Fig.2), non of flat Hyperplasia and CIS cases were positive for CD 44(Fig.8). However CD 44 were positive in $42.9 \%$ of atypia of unknown significance and $14.3 \%$ of Dysplasia.

Table3: Immunohistochemical reactivity pattern of cytokeratin 20 in selected flat lesions of the urinary bladder

$\begin{array}{llll}\text { Negative interpretation } & \text { Positive interpretation } & \mathbf{X}^{2} & \text { P }\end{array}$

\begin{tabular}{|c|c|c|c|c|c|c|c|}
\hline \multirow[t]{2}{*}{ Flat lesions } & \multirow[t]{2}{*}{ No } & & & & & & \\
\hline & & No & $\%$ & No & $\%$ & & \\
\hline Flathyperplasia & 1 & 1 & 100.0 & 0 & 0.0 & 0.1 & 0.75 \\
\hline reactive urothelial atypia & 14 & $13 * *$ & 92.9 & 1 & 7.1 & 23.6 & $<0.001 * *$ \\
\hline $\begin{array}{l}\text { atypia of unknown } \\
\text { significance }\end{array}$ & 7 & 3 & 42.9 & 4 & 57.1 & 0.001 & 0.9 \\
\hline Dysplasia & 21 & 2 & 9.5 & $19 *$ & 90.5 & 9.2 & $0.002 *$ \\
\hline carcinoma in situ(CIS) & 17 & 2 & 11.8 & $15^{*}$ & 88.2 & 5.63 & $0.017^{*}$ \\
\hline Total & 60 & 21 & 35.0 & 39 & 65.0 & & \\
\hline
\end{tabular}

CK 20 were positive in $90.5 \%$ of cases of Dysplasia. Non of Flat Hyperplasia were positive for CK 20 .However CK 20 were positive in $88.2 \%$ of CIS(Fig. 10), $57.1 \%$ of atypia of unknown significance and $7.1 \%$ of reactive urothelial atypia(Fig.3) . 
Table(4): ki67 expression in selected flat lesions of the urinary bladder:

\begin{tabular}{|c|c|c|c|c|c|c|c|}
\hline \multirow{3}{*}{$\begin{array}{c}\text { Flat } \\
\text { lesions }\end{array}$} & \multirow{3}{*}{ No } & \multicolumn{4}{|c|}{ ki 67 immunostaining } & \multirow{3}{*}{$X^{2}$} & \multirow{3}{*}{$\mathbf{P}$} \\
\hline & & \multicolumn{2}{|c|}{ low $<15 \%$} & \multicolumn{2}{|c|}{ high $>15 \%$} & & \\
\hline & & No & $\%$ & No & $\%$ & & \\
\hline Flat hyperplasia & 1 & 1 & 100.0 & 0 & 0.0 & 0.001 & 0.97 \\
\hline reactive urothelial atypia & 14 & 12 & $85.7 *$ & 2 & 14.3 & 10.2 & $0.0013 *$ \\
\hline $\begin{array}{l}\text { atypia of unknown } \\
\text { significance }\end{array}$ & 7 & 3 & 42.9 & 4 & 57.1 & 0.01 & 0.92 \\
\hline Dysplasia & 21 & 10 & 47.6 & 11 & 52.4 & 0.01 & 0.93 \\
\hline carcinoma in situ (CIS) & 17 & 3 & 17.6 & $14^{*}$ & 82.4 & 8.94 & $0.002 *$ \\
\hline$\overline{\text { Total }}$ & 60 & 29 & 48.3 & 31 & 51.7 & & \\
\hline
\end{tabular}

ki 67 index were high in $82.4 \%$ of cases of CIS(Fig. 11), non of Flat Hyperplasia express high ki 67 index. However ki 67 index were high in $57.1 \%$ of atypia of unknown significance, $52.4 \%$ of dysplasia and $14.3 \%$ of reactive urothelial atypia(Fig.6).

Table 5: CD 44 and CK20 immunoprofile of flat epithelial lesions of the urinary bladder :

\begin{tabular}{|c|c|c|c|c|c|c|c|c|c|c|c|}
\hline & \multirow{3}{*}{ No } & \multicolumn{8}{|c|}{ Immunoprofile of flat lesions } & \multirow{3}{*}{$\mathbf{X}^{2}$} & \multirow{3}{*}{$\mathbf{P}$} \\
\hline & & \multicolumn{2}{|c|}{ CD44-/CK20- } & \multicolumn{2}{|c|}{$\begin{array}{c}\text { CD44+/ CK20 } \\
+ \\
\end{array}$} & \multicolumn{2}{|c|}{ CD44+/ CK20- } & \multicolumn{2}{|c|}{ CD 44-/ CK20+ } & & \\
\hline & & No & $\%$ & No & $\%$ & No & $\%$ & No & $\%$ & & \\
\hline Flat hyperplasia & 1 & $1 *$ & 100.0 & 0 & 0.0 & 0 & 0.0 & 0 & 0.0 & 9.15 & $0.02 *$ \\
\hline $\begin{array}{l}\text { reactive urothelial } \\
\text { atypia }\end{array}$ & 14 & 0 & 0.0 & 1 & 7.1 & 13 & $92.9 * *$ & 0 & 0.0 & 45.8 & $<0.001 * *$ \\
\hline $\begin{array}{l}\text { atypia of unknown } \\
\text { significance }\end{array}$ & 7 & 1 & 14.25 & 1 & 14.25 & 2 & 28.6 & 3 & 42.9 & 0.79 & 0.85 \\
\hline Dysplasia & 21 & 2 & 9.5 & $3 *$ & 14.3 & 0 & 0.0 & $16^{*}$ & 76.2 & 11.63 & $0.008 *$ \\
\hline $\begin{array}{l}\text { carcinoma in } \\
\operatorname{situ}(\mathrm{CIS})\end{array}$ & 17 & $2 *$ & 11.8 & 0 & 0.0 & 0 & 0.0 & $15^{*}$ & 88.2 & 12.15 & $0.006^{*}$ \\
\hline Total & 60 & 6 & 10.0 & 5 & 8.3 & 15 & 25.0 & 34 & 56.7 & & \\
\hline
\end{tabular}

$100 \%$ of Flat Hyperplasia expressed CD44-/CK20-immunoprofile. (CD44+/ CK20-) immunoprofile were expressed in $92.9 \%$ of reactive urothelial atypia, 28.6 of atypia of unknown significance. However non of dysplasia or CIS cases expressed (CD44+/ CK20- ) immunoprofile.

(CD 44-/ CK20+) immunoprofile were expressed in $88.2 \%$ of CIS, $76.2 \%$ of dysplasia and $42.9 \%$ of atypia of unknown significance, 28.6 of. However non of flat hyperplasia or reactive urothelial atypia expressed (CD 44-/ CK20+)

Table 6: CK20 and Ki 67 immunoprofile of flat epithelial lesions of the urinary bladder:

\begin{tabular}{|c|c|c|c|c|c|c|c|c|c|c|c|}
\hline & \multirow{3}{*}{ No } & \multicolumn{8}{|c|}{ Immunoprofile of flat lesions } & \multirow{3}{*}{$\mathbf{X}^{2}$} & \multirow{3}{*}{$\mathbf{P}$} \\
\hline & & \multicolumn{2}{|c|}{ CK20-/Ki67- } & \multicolumn{2}{|c|}{ CK20+/ Ki67+ } & \multicolumn{2}{|c|}{ CK20+/ Ki67- } & \multicolumn{2}{|c|}{ CK20-/Ki67+ } & & \\
\hline & & No & $\%$ & No & $\%$ & No & $\%$ & No & $\%$ & & \\
\hline$\overline{\text { Flat hyperplasia }}$ & $\overline{1}$ & $\overline{1}$ & 100.0 & 0 & 0.0 & 0 & 0.0 & 0 & 0.0 & 2.8 & 0.42 \\
\hline $\begin{array}{l}\text { reactive } \\
\text { urothelialatypia }\end{array}$ & 14 & $11 * *$ & 78.6 & 0 & 0.0 & 1 & 7.1 & 2 & 14.3 & 28.9 & $<0.001 * *$ \\
\hline $\begin{array}{l}\text { atypia of unknown } \\
\text { significance }\end{array}$ & 7 & 2 & 28.6 & 3 & 42.8 & 1 & 14.3 & 1 & 14.3 & 0.4 & 0.9 \\
\hline Dysplasia & 21 & 2 & 9.5 & $11 *$ & 52.4 & $8 *$ & 38.1 & 0 & 0.0 & 9.71 & $0.02 *$ \\
\hline $\begin{array}{l}\text { carcinoma in } \\
\text { situ(CIS) }\end{array}$ & 17 & 0 & 0.0 & $12^{*}$ & 70.6 & $3 *$ & 17.6 & $2 *$ & 11.8 & 9.58 & $0.02 *$ \\
\hline Total & 60 & 16 & 26.7 & 26 & 43.3 & 13 & 21.7 & 5 & 8.3 & & \\
\hline
\end{tabular}

Both CK 20 and ki 67 were negative in 100\% of Flat Hyperplasia, non of CIS were negative for the two markers together. However both CK 20 and ki 67 were negative in $78.6 \%$ reactive urothelial atypia, $28.6 \%$ of atypia of unknown significance and $9.5 \%$ of dysplasia. 
Both CK 20 and ki 67 were positive in $70.6 \%$ of CIS cases, non of Flat Hyperplasia or reactive urothelial atypia were positive for the two markers together. However both CK 20 and ki 67 were positive in $52.4 \%$ of dysplasia and $42.8 \%$ of atypia of unknown significance

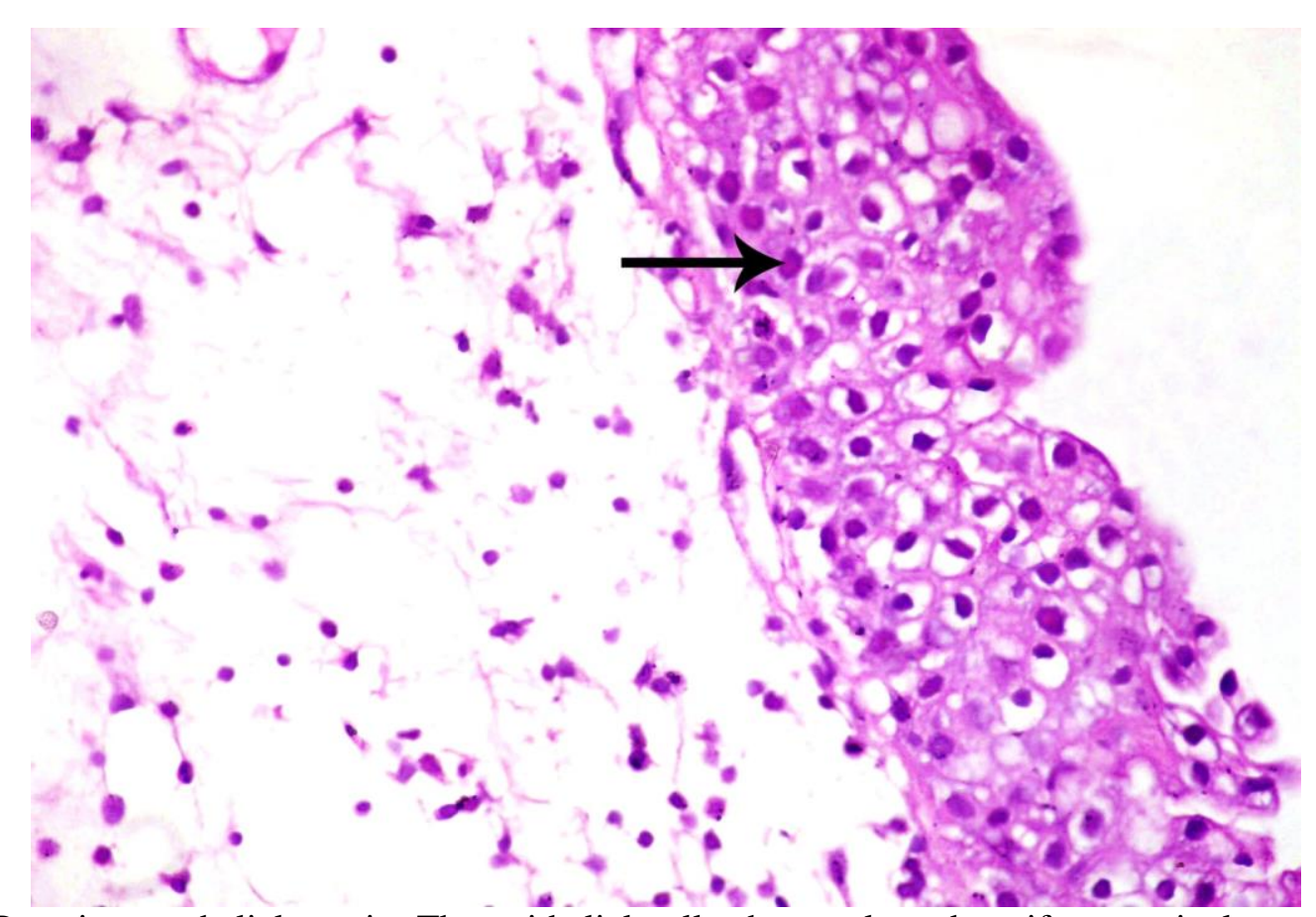

Fig. (1): Reactive urothelial atypia. The epithelial cells show enlarged uniform vesicular nuclei(arrow), some with Prominent central nucleoli. Mitotic figures are confined to the basal epithelial layers (Hx \& E X 400)

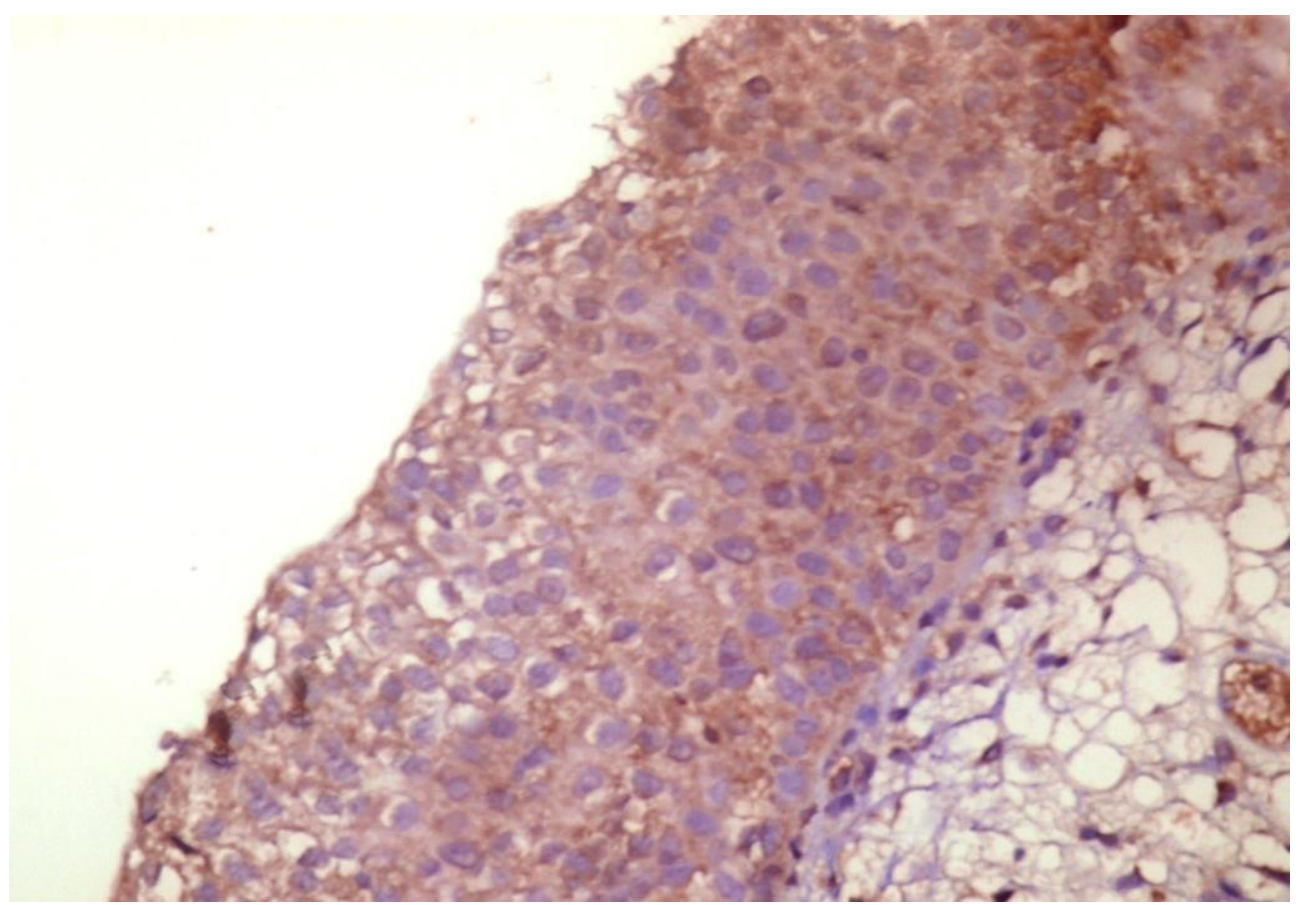

Fig. (2): Reactive urothelial atypia showing diffuse and strong membranous immunoreactivity for CD 44 (DAB chromogen. Mayer's hematoxylin (M.H) counter stain X400). 


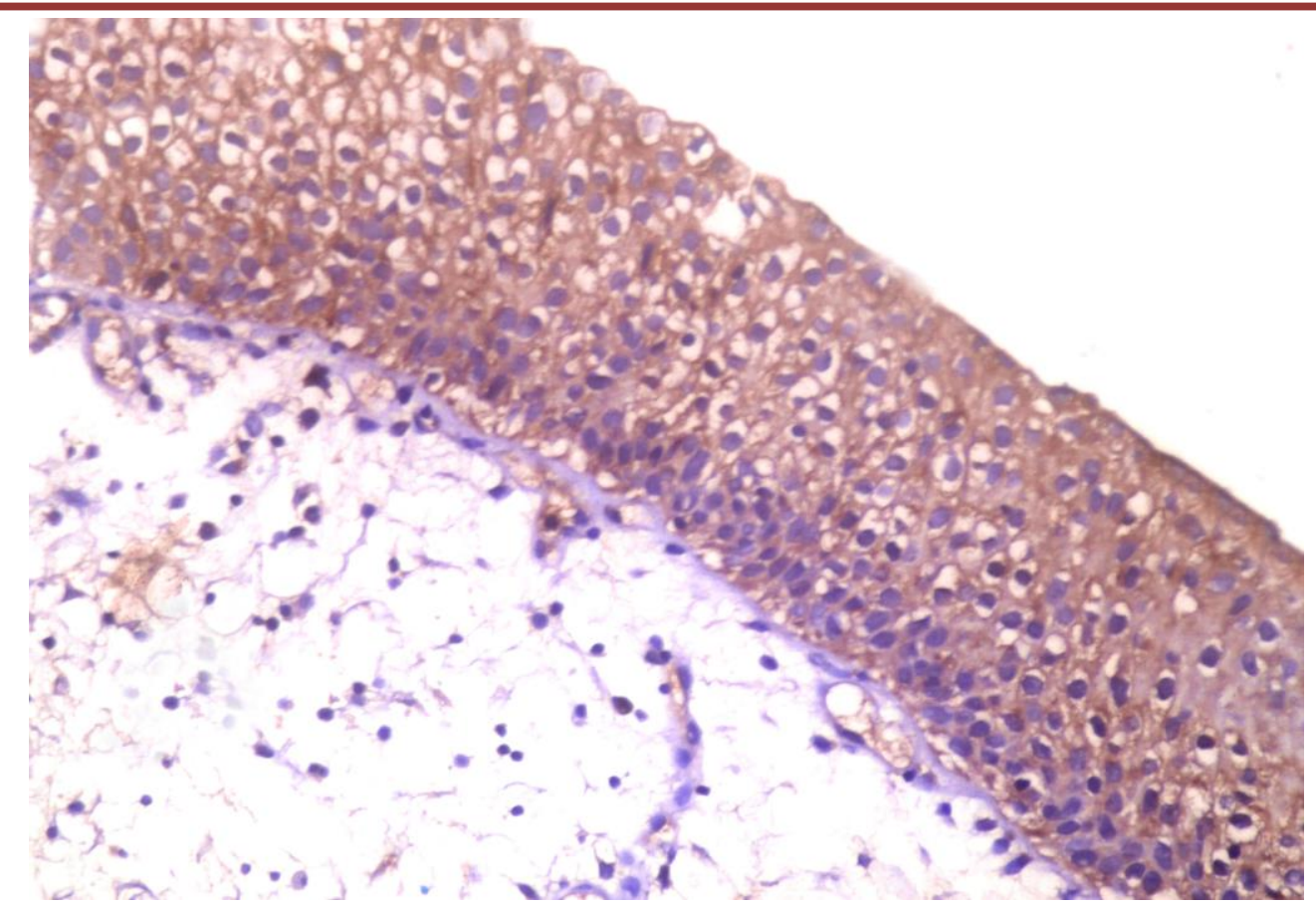

Fig. (3): Reactive urothelial atypia showing moderate diffuse cytoplasmic immunoreactivity for CK 20 (DAB chromogen. M.H counter stain X400).

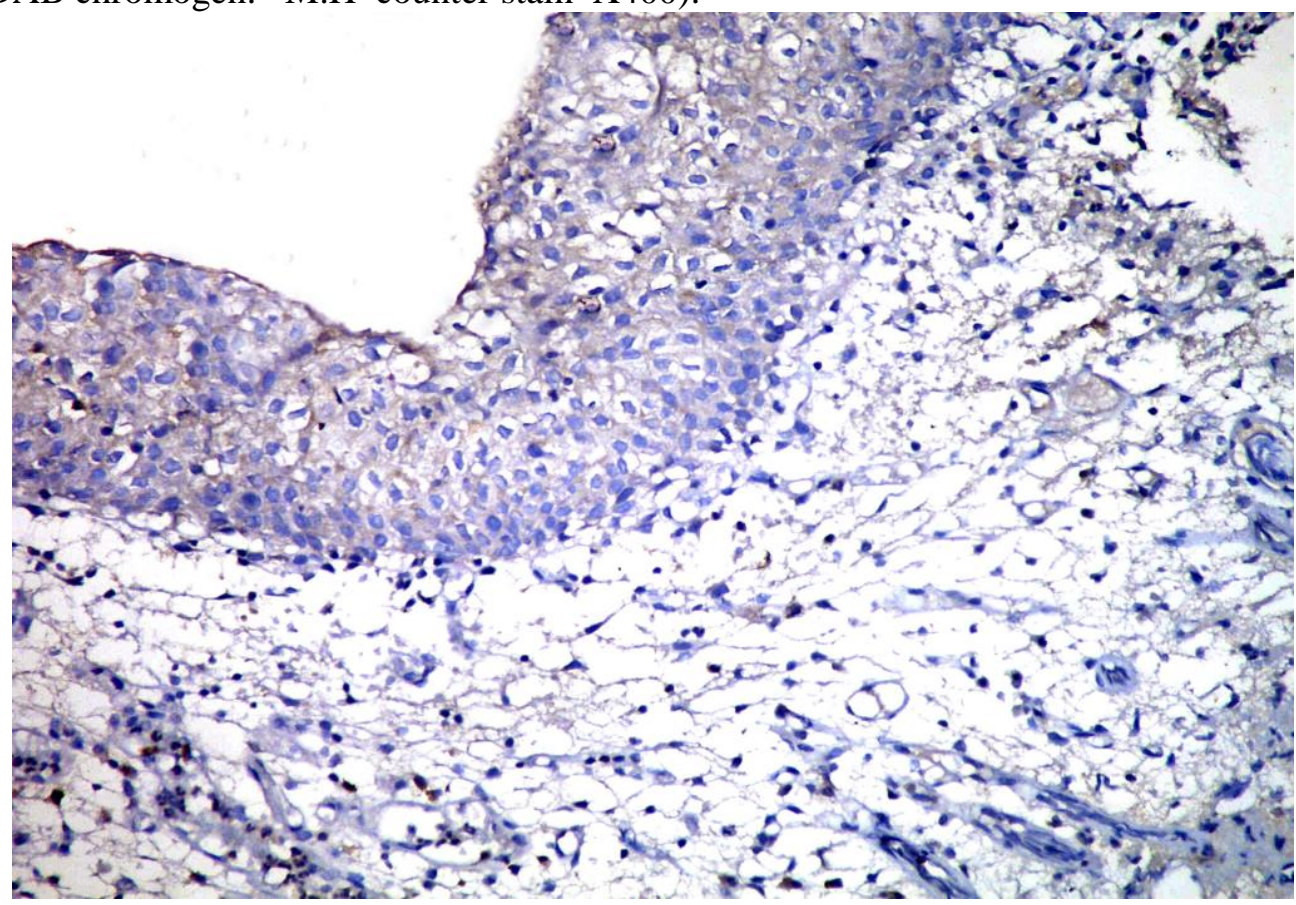

Fig. (4): Reactive urothelial atypia showing negative immunoreactivity for CK 20 (DAB chromogen. Mayer's hematoxylin M.H counter stain X 200). 


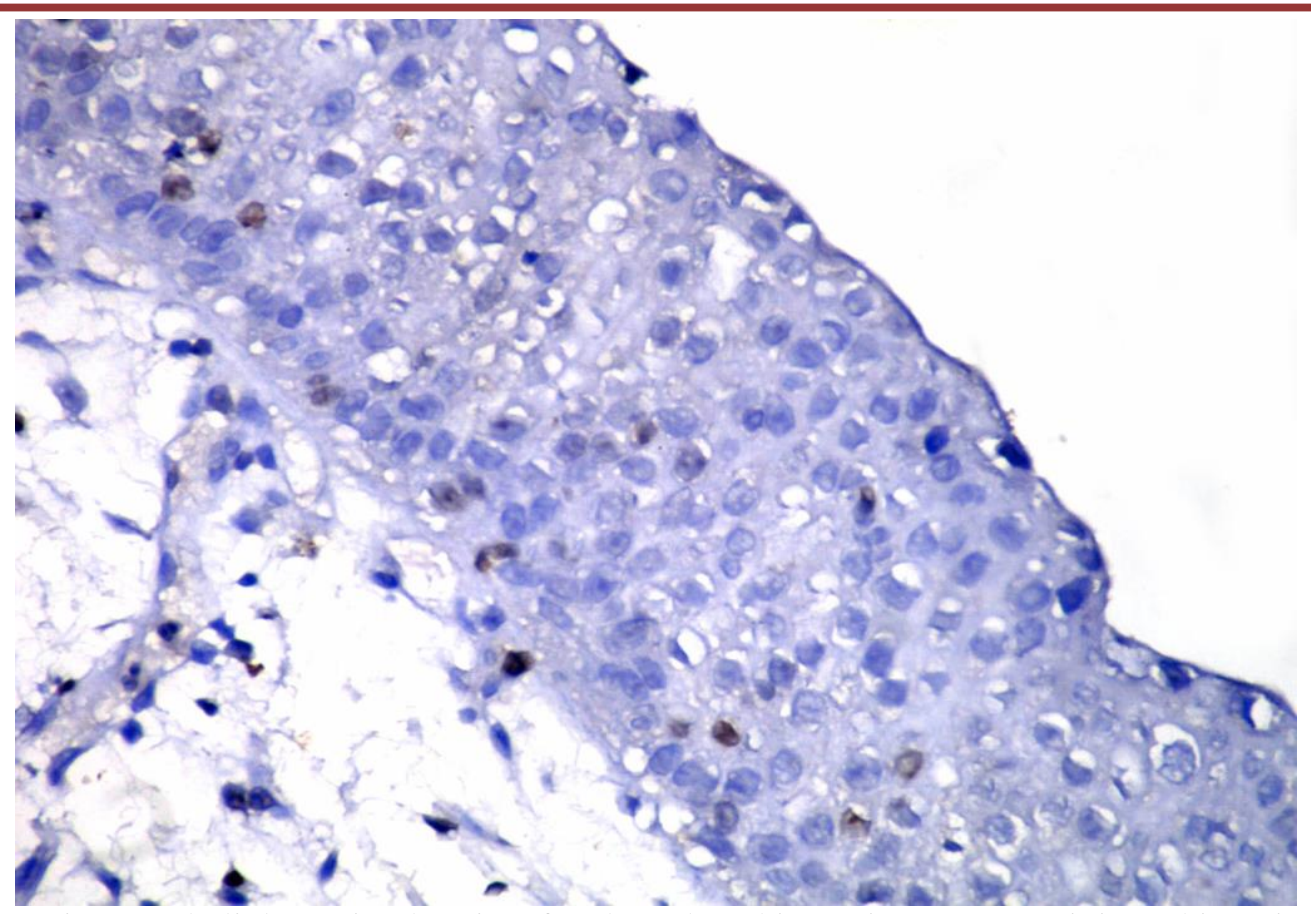

Fig. (5): Reactive urothelial atypia showing focal nuclear ki- 67 immunoreactivity (ki-67 index < 15\%) (DAB chromogen. M.H counter stain X400).

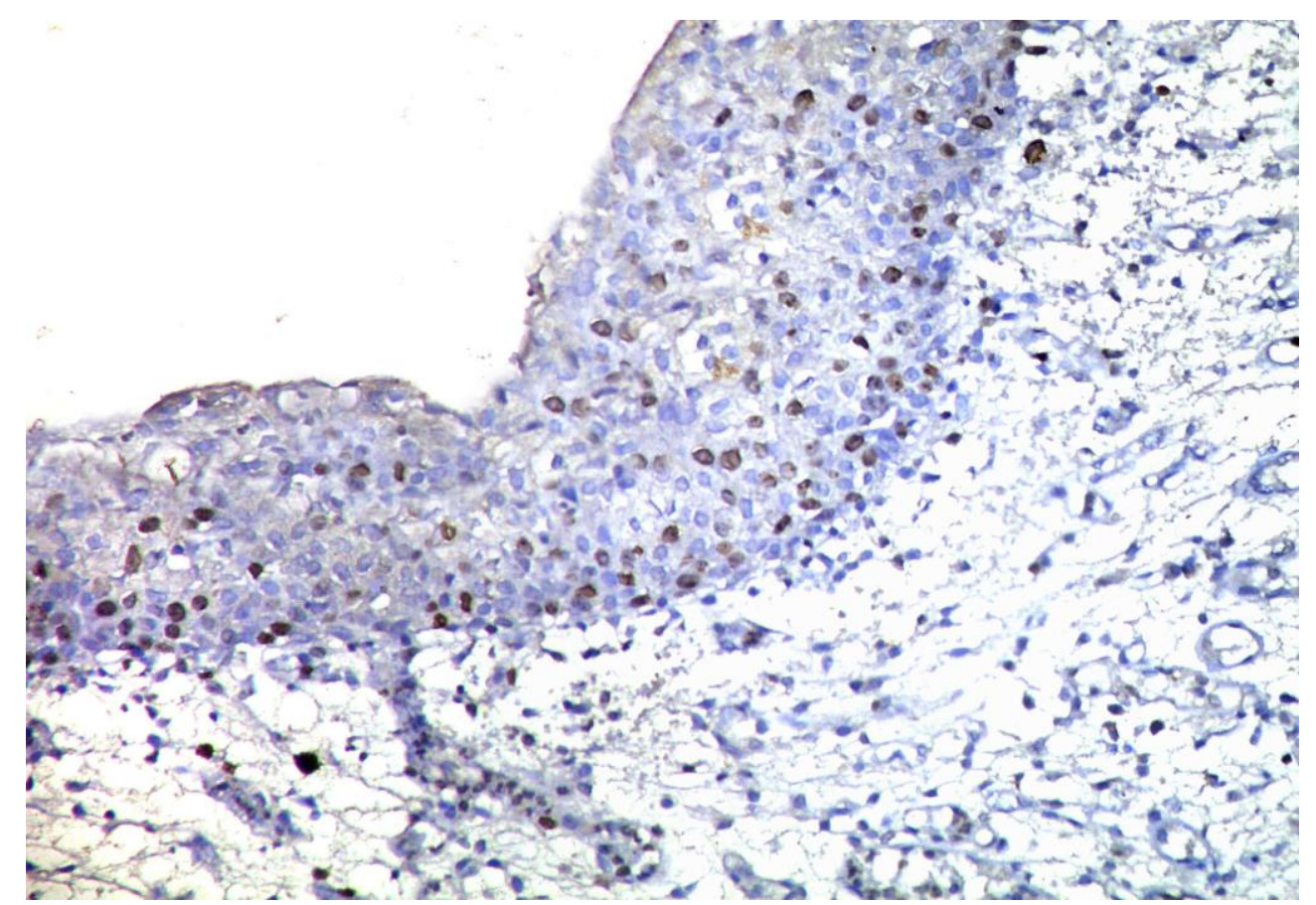

Fig. (6): Reactive urothelial atypia showing diffuse nuclear ki-67 immunoreactivity (ki- 67 index $>15 \%$ ) (DAB chromogen. Mayer's hematoxylin M.H counter stain X 200). 


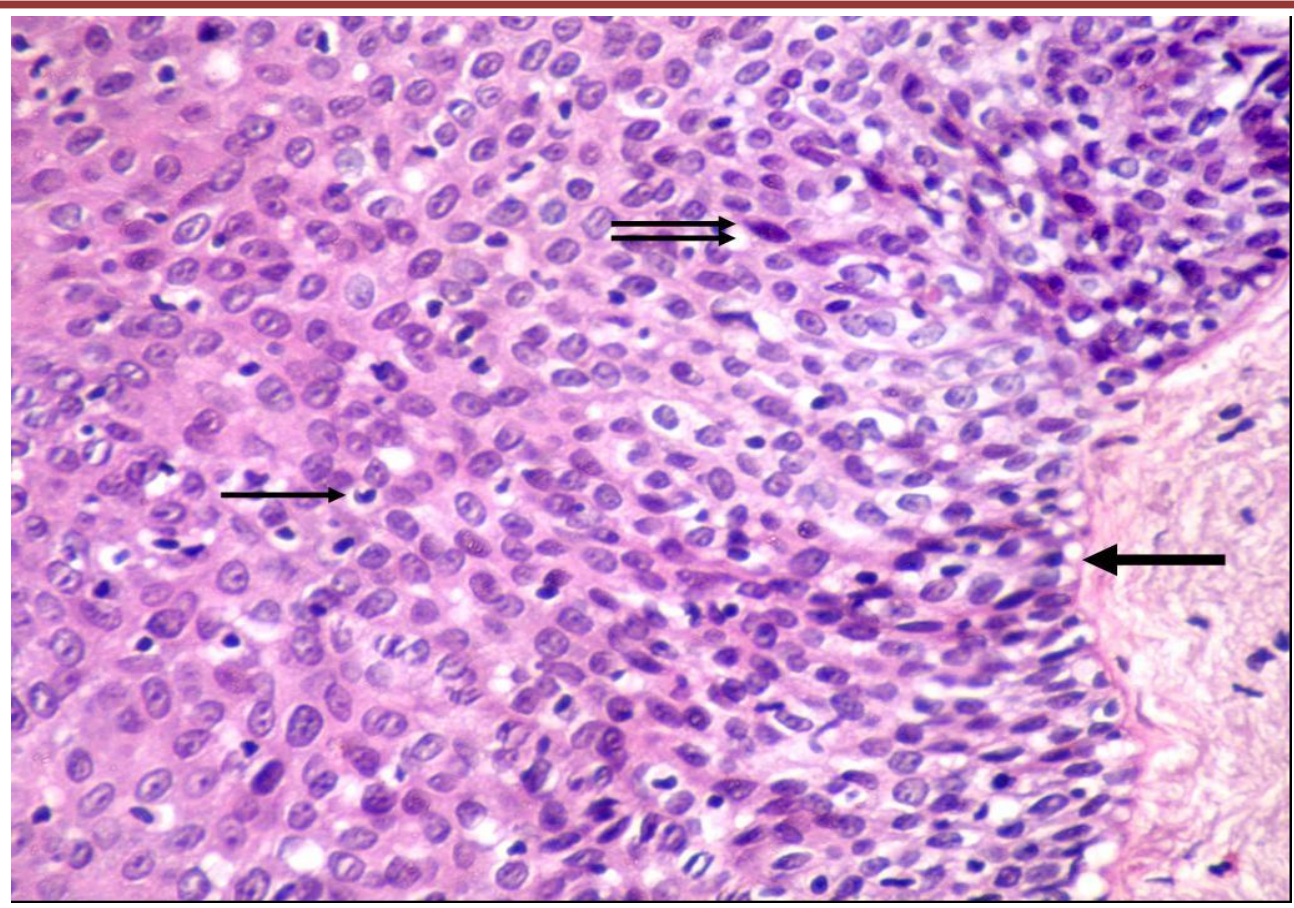

Fig. (7): Urothelial carcinoma in situ (CIS) demonstrating markedly thickened urothelium, disordered proliferation of pleomorphic malignant urothelial cells with a high nuclear to cytoplasmic ratio (double arrow). The cell nuclei are enlarged hyperchromatic nuclear with irregular nuclear contours, coarse granular chromatin and large prominent nucleoli . There is loss of Cellular polarity. Atypical mitotic figures are seen in whole epithelial thickness (thin arrow). Basement membrane is intact (thick arrow) (Hx \& E X 400).

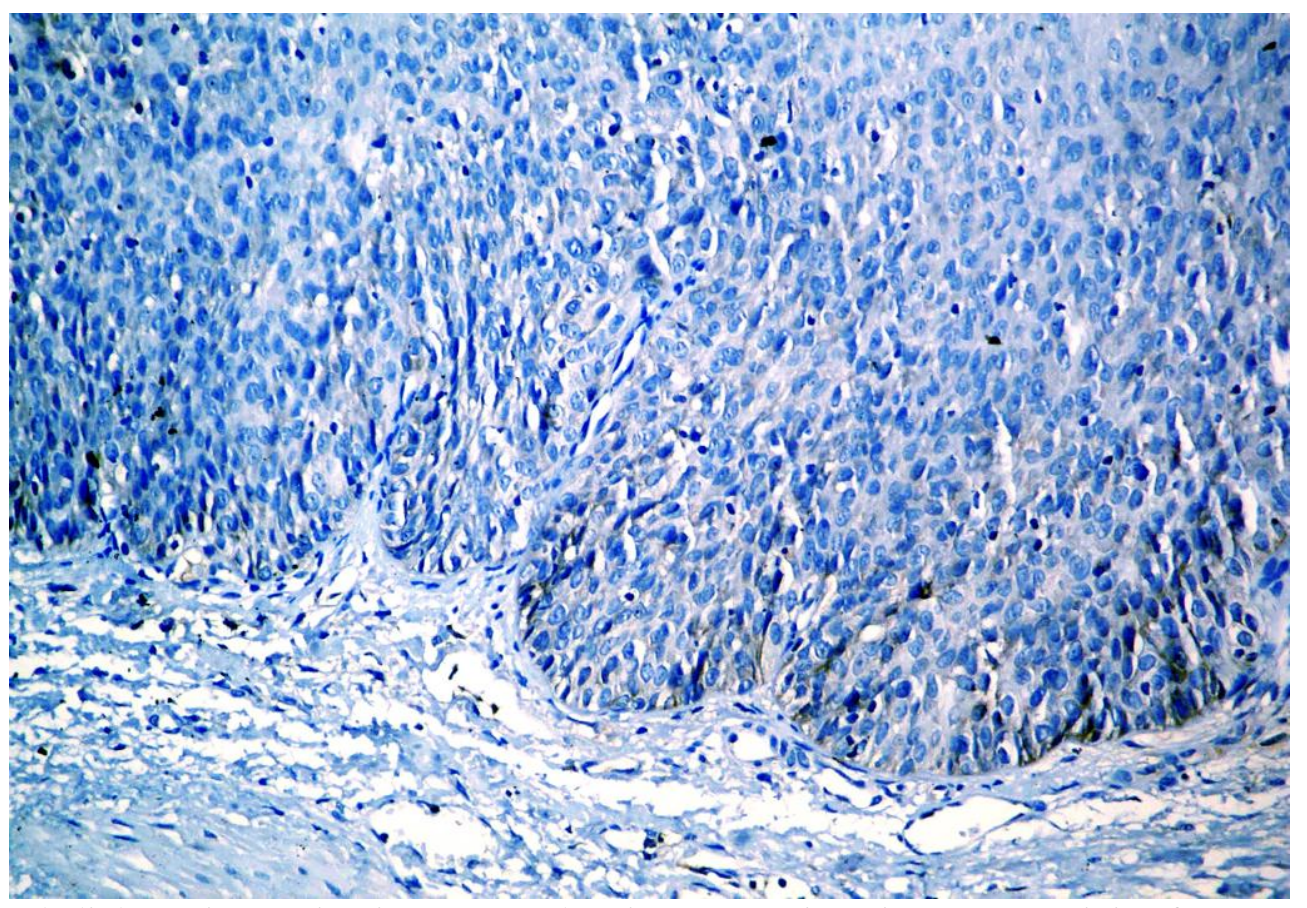

Fig. (8): Urothelial carcinoma in situ (CIS) showing negative immunoreactivity for CD 44 (DAB chromogen. Mayer's hematoxylin M.H counter stain X 200). 


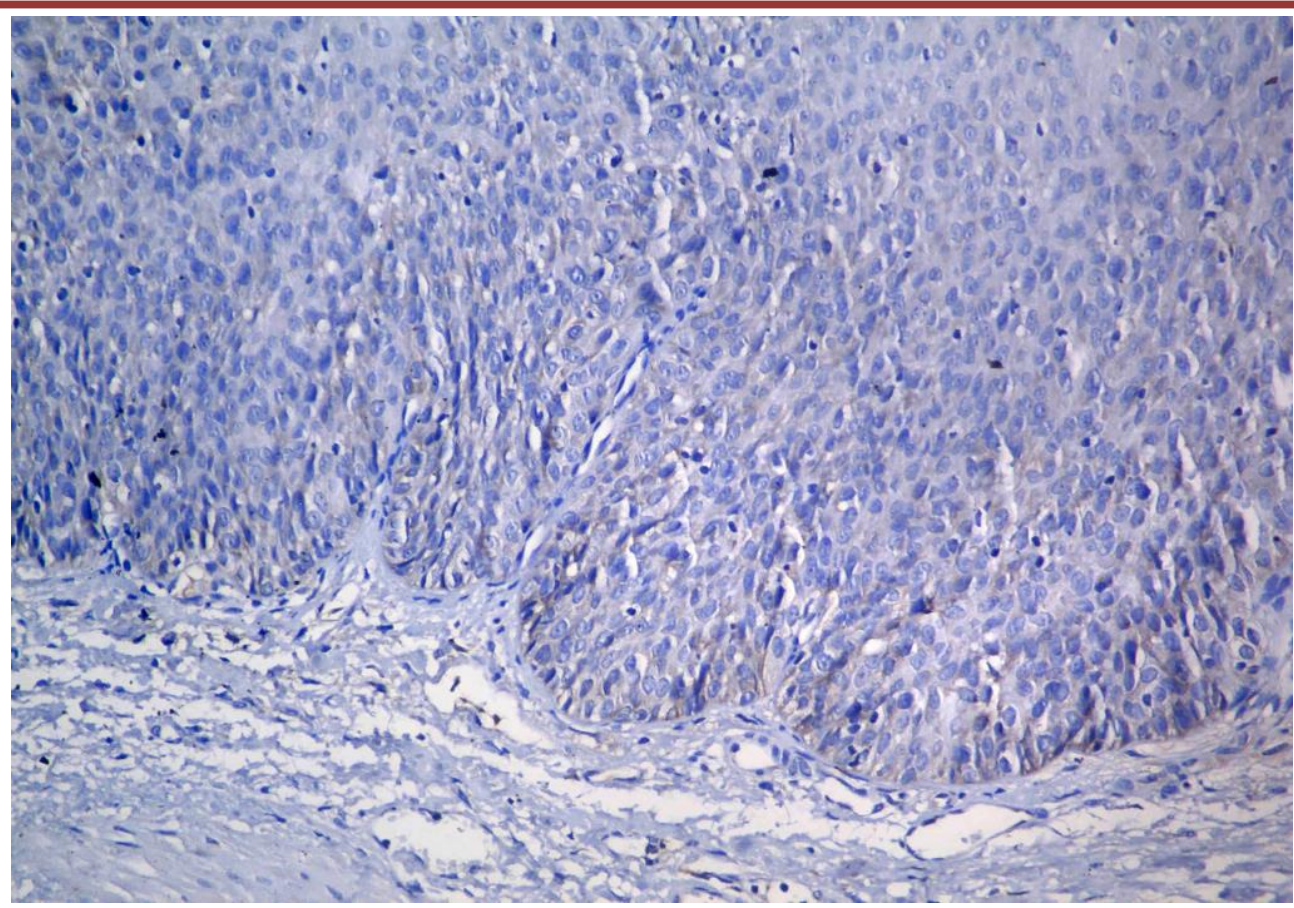

Fig. (9): Urothelial carcinoma in situ (CIS) showing negative immunoreactivity for CK 20 (DAB chromogen. Mayer's hematoxylin M.H counter stain X 200).

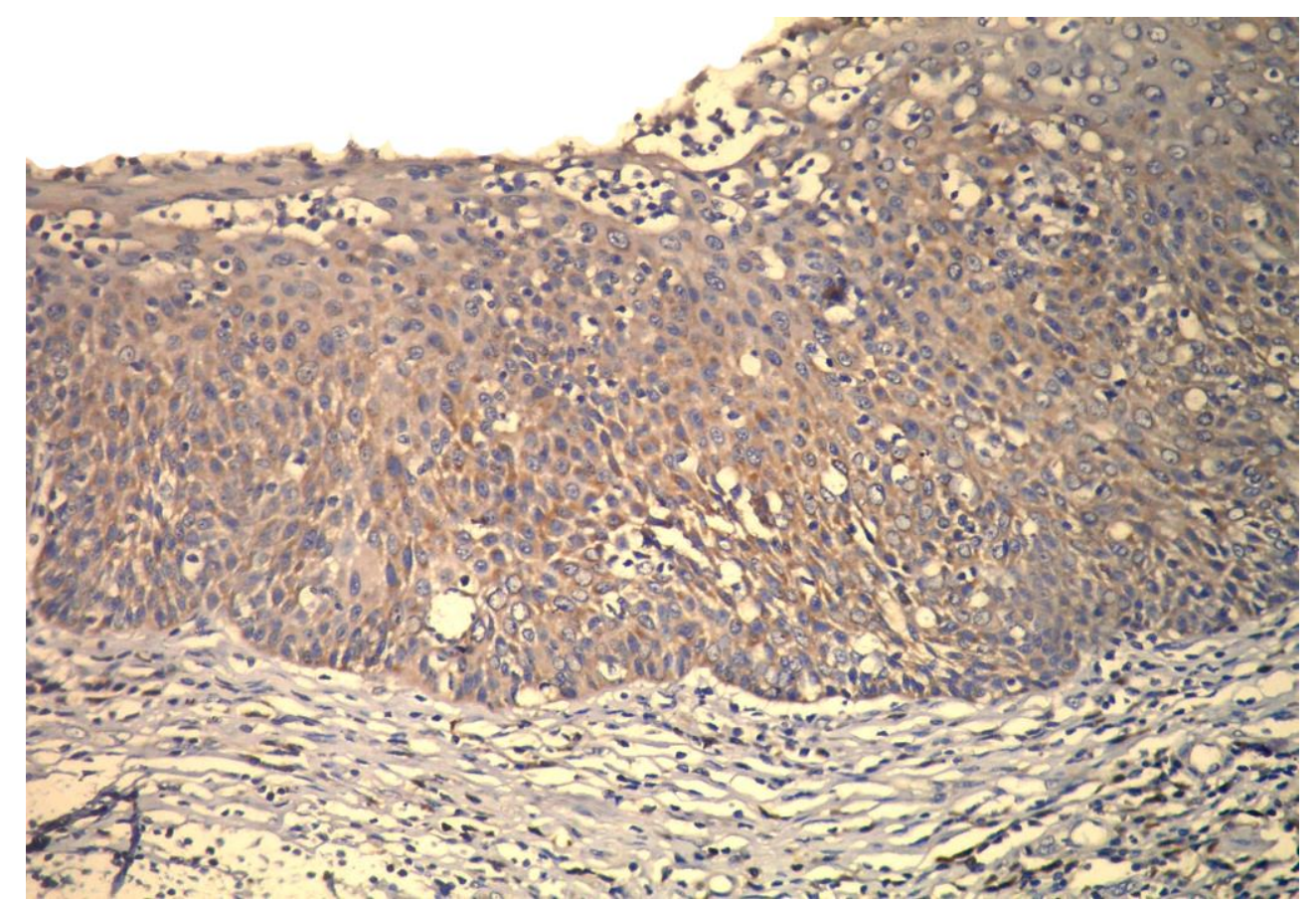

Fig. (10): Urothelial carcinoma in situ (CIS) showing moderate diffuse cytoplasmic Immunoreactivity for CK 20 (DAB chromogen. Mayer's hematoxylin M.H counter stain X 200). 


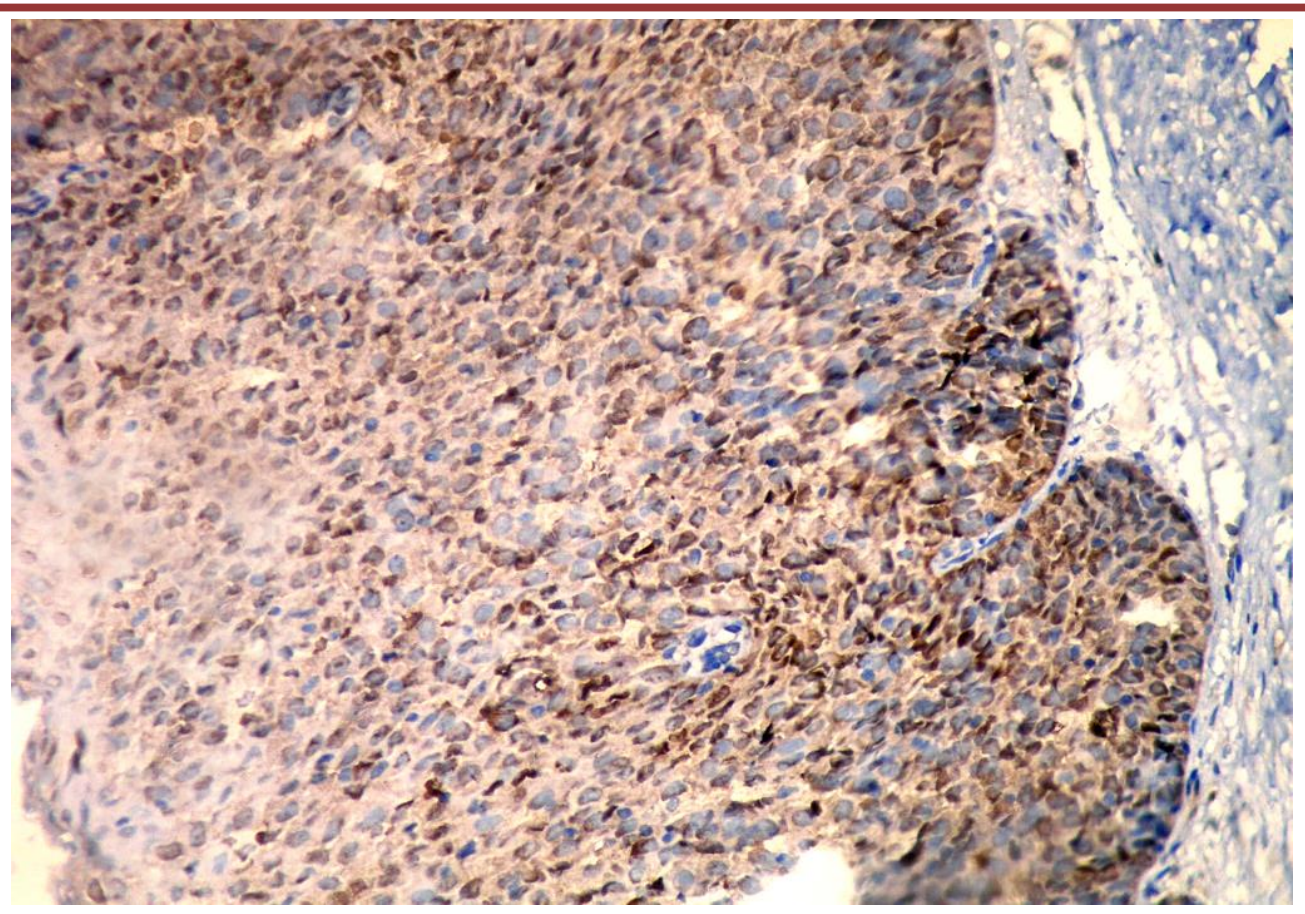

Fig. (11): Urothelial carcinoma in situ (CIS) showing diffuse nuclear ki-67 immunostain (ki-67 index > 15\%) (DAB chromogen. Mayer's hematoxylin M.H counter stain X 200).

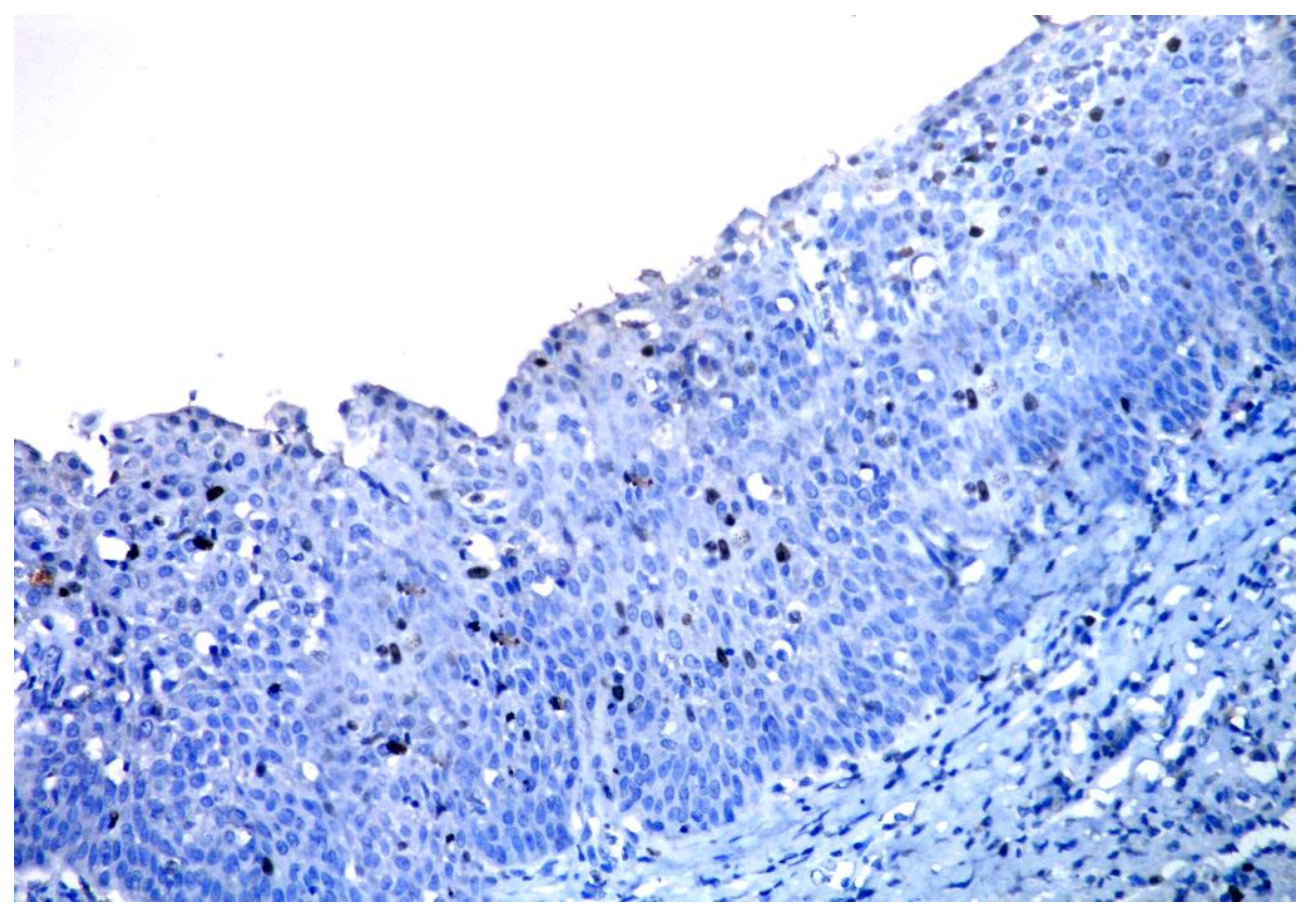

Fig. (12): Urothelial carcinoma in situ (CIS) showing focal nuclear ki- 67 immunostain (ki-67 index < 15\%) (DAB chromogen. Mayer's hematoxylin M.H counter stain X 200).

\section{DISCUSSION}

Even after publication of the WHO/ ISUP classifications, the distinction between reactive and dysplastic changes has not been resolved, There are still no definite morphological criteria to diagnose CIS, and there is great inter- and intraobserver disagreement .So morphology alone is frequently insufficient to differentiate dysplasia/CIS from reactive urothelial atypia.

The distinction is critical because it has both therapeutic and prognostic implications. Several studies had reported the utility of CD44, CK 20 and KI-67 in the diagnosis of flat epithelial lesions of the urinary bladder ${ }^{(14,15,18,19,20)}$. 
In our present a statistically significant relationship was observed between age $<50$ and the presence of isolated flat lesions. There is also a significant association between age $>70$ and the presence of flat lesions(dysplasia/CIS) in association with carcinoma This goes with previous studies by Cheng et al. ${ }^{(21)}$, Demir et al. ${ }^{(22)}$, Fernando et al. ${ }^{(23)}$, Garbar et al. ${ }^{(24)}$ and Takenaka et al. $^{(9)}$. In the present study, the majority of the studied cases of flat lesions including CIS were males (88.3\%). This agrees with Jemal et al. ${ }^{(25)}$ who reported the majority of the studied CIS cases were males. However our cases were randomly selected, thereby an accurate significant value regarding age and sex cannot be given.

One case of flat hyperplasia was included in this study, it was negative for (CD 44 and CK 20) and expressed low ki 67 index (table 2,3,4). This immunohistochemical profile is similar to that of normal urothelium. Similar pattern is reported by Hodges et al. ${ }^{(\mathbf{1})}$. This finding supported that flat hyperplasia does not have a premalignant potential

The studied 14(100\%) cases of reactive urothelial atypia were positive for CD $44.9(64 \%)$ out of them showed full thickness membranous overexpression of CD 44 and 5(36\%) out of them showed patchy positivity in the urothelium (table 2).

. This is in agreement with McKenney et al. ${ }^{(15)}$ who found membranous full thickness over expression of CD44 in (60\%) of their studied reactive urothelial atypia and patchy positivity in the basal and intermediate cells (similar to normal urothelium) in (40\%) of them.

As regarding CK 20 in the studied 14 cases of reactive urothelial atypia, 13(92.9\%) were negative for CK 20. There is one case that was positive for CK 2(table 3) but this is considered as non-specific because of benign morphology, positivity for CD44 and low ki 67 index. This result is close to the result of Kunju et al. ${ }^{(14)}$ who had $(96 \%)$ of RUA negative with CK20 beneath the superficial umbrella layer and had one case (4\%) of morphological clear-cut RUA showing focal full thickness CK20 expression that interpreted by them as non-specific because it was patchy with benign morphology. They stated that abnormal CK20 staining may occur on rare occasions; therefore correlation with morphology is critical. They mentioned that CK20 expression in the superficial umbrella cells of fragmented epithelial fragments opposed to each other may give a false impression of a full-thickness staining pattern of UD. In a previous studies by McKenney et al. ${ }^{(15)}$ and Mallofre et al. ${ }^{(19)}$ found that CK20 staining only the umbrella cell layer in $(100 \%)$ of their studied reactive urothelial atypia.

Concerning Ki 67 expression in the studied 14 cases of reactive urothelial atypia, low ki 67 index was observed in 12/14(85.7\%) and high ki 67 index was observed in $2 / 14(14.3 \%)$, these cases were associated with severe inflammation(table 4). The high ki 67 index in these cases were considered non-specific after correlation with benign morphology, and other immunostain (positive CD44 and negative CK 20). This is in agreement with Kunju et al.(14) who found $28 \%$ of morphologically clear-cut RUA also had increased expression, especially when associated with severe inflammation. So caution must be exercised when interpreting this antibody in an inflamed urothelium.

Seven cases of atypia of unknown significance were found in this study, $3 / 7$ (42.9\%) were positive for CD44 and 4/7 (57.1\%) were negative for CD44(table 2). As regarding CK 20 in the studied 7 cases of atypia of unknown significance, 4/7 (57.1\%) were positive for CK 20 and 3/7 (42.9\%) were negative for CK 20(table 3). Concerning Ki 67 expression in the studied 7 cases of atypia of unknown significance low Ki 67 index was observed in $3 / 7$ (42.9\%) and it was high in 4/7 (57.1\%) (table 4) .

The three markers were evaluated together and correlated with the morphology to reach a diagnosis. Six cases were categorized as reactive versus dysplastic .A total of $4 / 7(57.1 \%$ ) were rediagnosed as dysplasia. All the 4 cases (4/7) were positive for CK 20, of which 2 cases (2/4) also demonstrated high ki 67 index and were negative for CD44; these two cases were favored to be categorized as dysplasia. In one case (1/4) ki 67 index was high but it was positive for CD44, the abnormal expression of both CK 20 and ki 67 made the diagnosis of dysplasia more likely. In other case(1/4) ki 67 index was low, however CD44 was negative, this case was also thought to be dysplasia because of the abnormal expression of both CK 20 and CD44 and correlation with the morphology. Our result goes with Kunju et al.(14) who mentioned that the greatest value of a panel of immunostains would be the ability to resolve cases of AUS and realized that AUS is not a disease or a diagnostic entity but merely a descriptive term used in diagnostically difficult cases. On the other hand, Mallofre et al.(19) found $75 \%$ of atypia of unknown significance suggested to be dysplastic. They based their suggestion on strong positivity in scattered suspected dysplastic cells through the epithelium to at least one marker.

As regarding CD 44 immunohistochemical reactivity in dysplasia and CIS, in 21 cases of 
dysplasia CD 44 produced mixed result. While $18 / 21(85.7 \%)$ were negative, $3 / 21(14.3 \%)$ were positive for CD 44(table 2). . In all three cases abnormal CK 20 expression were observed. In Two cases(2/3) with abnormal CK 20 expression high ki 67 index were noted .only one of them $(1 / 3)$ showed low ki 67 index. However in CIS CD 44 were negative in $17(100 \%)$ cases .Such negativity ranged from complete absence of CD44 reactivity in 11( $64.7 \%$ ) out of them to residual CD44 membranous reactivity in the basal cell layer in 6(35.3\%). This result is closely related to that of McKenney et al. (2001) who found, a lack of CD44 reactivity in the neoplastic cells of all cases of CIS but in $44 \%$ of them, an underlying residual basal cell layer was present which showed CD44 membranous reactivity.

Concerning CK 20 immunohistochemical reactivity in dysplasia and CIS, in dysplasia, 19/21 (90.5\%) were positive for CK 20 and $2 / 21(9.5 \%)$ were negative for CK 20(table 3).. Unfortunately, such two cases also expressed low ki 67 index but they were negative for CD 44 . In the studied 17 cases of CIS, $15 / 17$ (88.2\%) were positive for CK 20 and $2 / 17$ (11.8\%) were negative for CK 20(table 3). Fortunately, such two cases expressed high ki 67 index and were negative for CD 44. This agrees with McKenney et al. ${ }^{(15)}$ who showed over expression of CK20 (cytoplasmic) in the majority ( $>50 \%$ ) of neoplastic cells in $81 \%$ of CIS.

Our result reflected similar findings by Kunju et al. ${ }^{(\mathbf{1 4})}$ who demonstrated abnormal CK20 expression in $86 \%$ (43/50) of UD/ CIS group and negative CK20 in 14\%. All seven cases of CIS that were negative with CK20, had unequivocal overexpression of Ki-67 (>50\% expression of Ki-67). They believed that although CK20 appears to be a fairly specific marker of urothelial dysplasia, a small subset of morphologically clear-cut CIS can be negative with this antibody. Increased Ki-67 expression in CIS cases negative with CK20 can usually resolve this problem. In their study, all CIS cases negative with CK20 showed unequivocal over expression with Ki-67. These results are nearly similar to that of Mallofre et al. ${ }^{(\mathbf{1 9})}$ who found that $72 \%(36 / 50)$ out of the CIS cases were positive for CK20. Through the full thickness of the urothelium. $86 \%$ of them (31/36) showing a strong full-thickness positivity of $>50 \%$ of atypical cells.

As regarding ki 67 expression in dysplasia and CIS, in dysplasia high $\mathrm{Ki} 67$ index was observed in 11/21 (52.4\%) while low Ki 67 index was observed Ki 67 in 10(47.6\%) (table4). Among Such 10 cases with low Ki 67 index, CK 20 were positive in $8(8 / 10)$ out of them but it were negative in 2(2/10) out of them . Fortunately, such two cases were negative for CD 44. In CIS high Ki 67 index was observed in $14 / 17(82.4 \%$ ) while low Ki 67 index was observed in 3/17 (17.6\%) (table 4).. Positive CK 20 and negative CD 44 solved the problem in these three cases. This result is near to the result of Mallofre et al. ${ }^{(19)}$.

In our study, there is a statistically significant difference between the reactive urothelium and dysplastic urothelium (dysplasia and CIS) as regarding their immunohistochemical reactivity for CD 44, CK 20 and Ki 67 submitted in the study. This is in agreement with McKenney et al. ${ }^{(15)}$ who demonstrated utility of CD-44 in reactive urothelium and Mallofre et al. ${ }^{(19)}$ and Kunju et al. ${ }^{(14)}$ who found CK20 and Ki-67 to be useful markers of UD/CIS.

Conclusion: According to our results, CD 44 is the most constant marker in the reactive urothelium. CK20 is the most commonly detected marker in the dysplastic urothelium. Nevertheless, the most accurate is application of an immunohistochemical panel composed of the three antibodies (standard CD 44, CK20 and Ki-67) together with correlation with morphology. This is very useful for confirming the presence of dysplastic changes in the urothelium and differentiating reactive urothelium from dysplastic urothelium (dysplasia/CIS).

\section{REFERENCES}

1. Hodges B K, Lopez-Beltran A, Davidson D D, Montironi $\mathrm{R}$ and Cheng L. Urothelial dysplasia and other flat lesions of the urinary bladder: clinicopathologic and molecular features.J Human Pathology (2010); 41: 155-162.

2. El-Mawla N.G., El-Bolkainy M.N. and Khaled H.M. Bladder cancer in Africa: Update. Semin Oncol(2001); 28(2): 178-8.

3. Eble JN, Sauter G, Epstein JI and Sesterhenn IA. World Health Organization classification of tumours: pathology and genetics of tumours of the urinary system and male genital organs. Lyon: IARC Press; (2004).

4. Cheng L., Lopez-Beltran A., MacLennan G.T., Montironi R. and Bostwick D.G. Neoplasms of the urinary bladder. In: Bostwick D.G. and Cheng L., Editors, Urologic surgical pathology . 2 nd ed. Elsevier/Mosby, Philadelphia (2008); 259-352.

5. Petersen R.O.,Sester I.A. and Davis C.J. Flat urothelial proliferations with significant malignant potential. In: Urologic pathology . $3 \mathrm{rd}$ ed. (2009); 214-251.

6. Montironi R., Lopez-Beltran A., Scarpelli M., Mazzucchelli R. and Cheng L. Morphological classification and definition of benign,preneoplastic and noninvasive neoplastic lesions of the urinary bladder. Histopathology (2008); 53: 621-633. 
7. Grignon D.J. The current classification of urothelial neoplasms. Mod Pathol (2009); 22 (2): 560-90.

8. Edge SB, Byrd DR, Compton CC, Fritz AG, Greene FL and Trotti A. American joint committee on cancer staging manual (7th ed.), Springer, New York (2010).

9. Takenaka A., Yamada Y., Miyake H., Hara I. and Fujisawa M. Clinical outcomes of Bacillus Calmette-Guerin instillation therapy for carcinoma in situ of urinary bladder, Int $\mathrm{J}$ Urol. (2008); 15: 309-313

10. Montironi R, Mazzucchelli R, Scarpelli M, Lopez-Beltran A and Cheng L: Morphological diagnosis of urothelial neoplasms. J Clin Pathol 2008, 61:3-10.

11. Cheng L, Cheville JC, Neumann RM and Bostwick DG. Flat intraepithelial lesions of the urinary bladder. Cancer (2000); 88: 625-31

12. Williamson S R., Montironi R, Lopez-Beltran A, MacLennan T , Davidson D D. and Cheng L. Diagnosis, evaluation and treatment of carcinoma in situ of the urinary bladder: The state of the art. Critical Reviews in Oncology/Hematology (2010) ;76: 112-126

13. Boman $\mathrm{H}$, Hedelin $\mathrm{H}$ and Holmang S. Four bladder tumor markers have a disappointingly low sensitivity for small size and low grade recurrence. J Urol 2002;167:80-3.

14. Kunju LP, Lee CT, Montie J and Shah RB. Utility of cytokeratin 20 and Ki-67 as markers of urothelial dysplasia. Pathol Int (2005); 55: 24854.

15. McKenney JK, Desai S, Cohen C and Amin MB. Discriminatory immunohistochemical staining of urothelial carcinoma in situ and non-neoplastic urothelium: an analysis of cytokeratin 20, p53, and CD44 antigens. Am J Surg Pathol (2001); 25: 1074-8.

16. Kogiku M., Ohsawa I., Matsumoto K., Sugisaki Y., Takahashi $\mathrm{H}$ and Teramoto A. Prognosis of glioma patients by combined immunostaining for survivin, Ki-67 and epidermal growth factor receptor. Journal of Clinical Neuroscience (2008) ;15: 1198-1203.

17. Bertz S, Otto W, Denzinger S, Wieland F. , Burger M, Sto“hr R, Link S , Hofsta“dter F and Hartmann A. Urothelial Cancer: Combination of CK20 and Ki-67 Immunostaining Analysis Predicts Recurrence, Progression, and Cancer-Specific Survival in pT1 Urothelial Bladder Cancer. European Urology (2 01 2); $4544: 1-9$.

18. Sun W, Zhang PL and Herrera GA. p53 protein and $\mathrm{Ki}-67$ overexpression in urothelial dysplasia of bladder. Appl Immunohistochem Mol Morphol2002; 10: 327-31.

19. Mallofre C, Castillo M, Morente V and Sole M. Immunohistochemical expression of CK20, p53, and Ki-67 as objective markers of urothelial dysplasia. Mod Pathol(2003); 16: 187-91.

20. Retz M, Lehmann J, Amann E, Wullich B, Roder $\mathrm{C}$ and Stockle M. Mucin 7 and cytokeratin 20 as new diagnostic urinary markers for bladder tumor.J Urol(2003);169: 86-9.

21. Cheng L, Cheville JC, Neumann RM and Bostwick DG. Natural history of urothelial dysplasia of the bladder. Am. J. Surg. Pathol. (1999); 23; 443-447.

22. Demir MA, RydW, Aldenborg F and Holmang S. Cytopathological expression of different types of urothelial carcinoma in situ in urinary bladder washings. BJU Int (2003);92:906-10

23. Fernando H, Thota SS, Burtt G, Waterfall N, Husain I. Importance of red patches diagnosed in cystoscopy for haematuria and lower urinary tract symptoms. Postgrad Med J (2007);83:62-3.

24. Garbar C., Mascaux C. and Wespes E. Is urinary tract cytology still useful for diagnosis of bladder carcinomas? A large series of 592 bladder washings using a five-category classification of different cytological diagnoses, Cytopathology (2007); 18: 79-83.

25. Jemal A, Siegel R, Ward E, Hao Y, Xu J and Thun MJ. Cancer statistics, 2009. CA Cancer J Clin 2009;59:225-49. 
أهمية الإصابات الطائية|لمسطحة للمثانة البولية فى الكثف المبكر لسرطان المثانة:دراسةهنتوباثولوجيه ومناعيه هستوكيميائيه

\section{الملخص العربي}

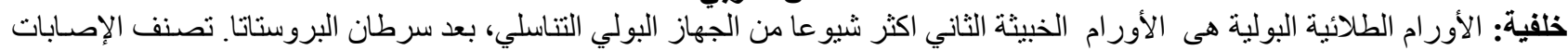

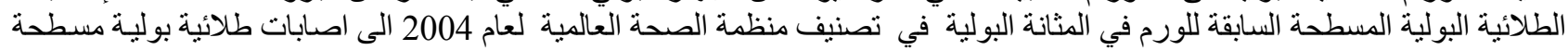

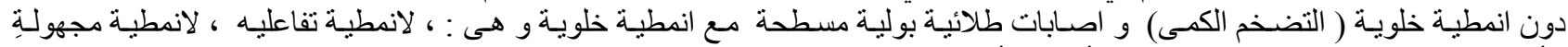

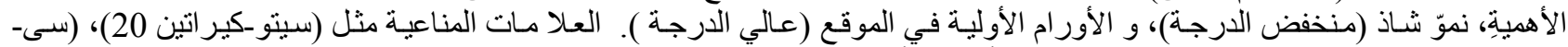

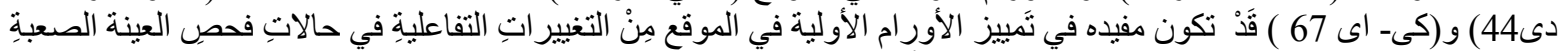

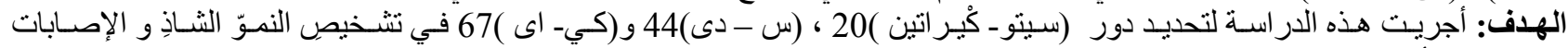
المسطحة الأخرى للمثنانة البولية.

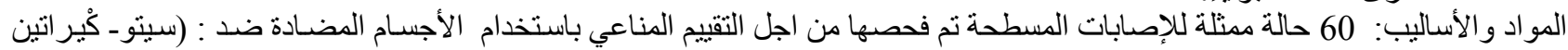

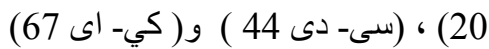

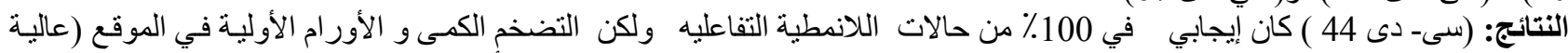

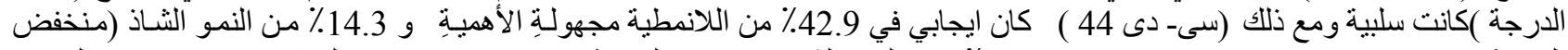

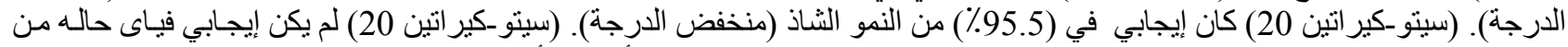

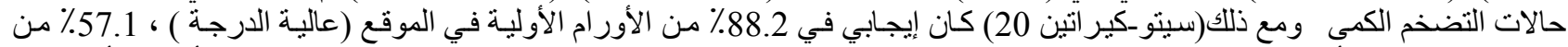

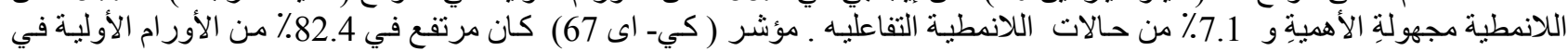

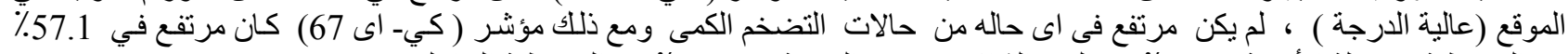

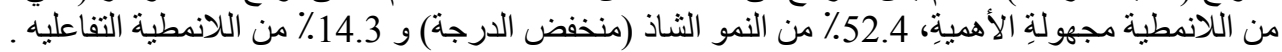

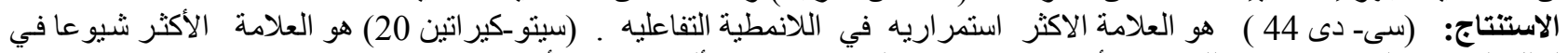

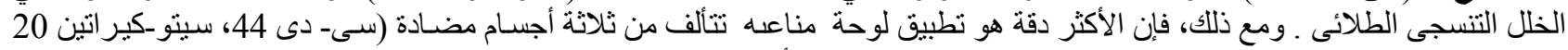

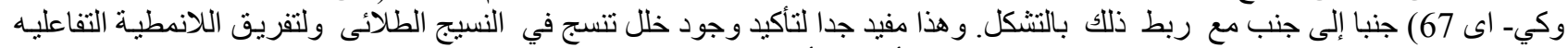

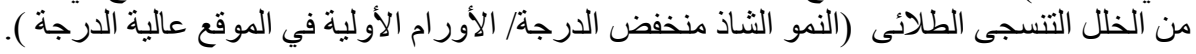

